\title{
Indigenizing English in the ESL Classroom: Decolonizing Knowledge for Epistemic Access in Spaces of Rurality
}

\author{
Sindiso Zhou \\ ORCID iD: https://orcid.org/0000-0002-0037-0218
}

Nhlanhla Landa

ORCID iD: https://orcid.org/0000-0002-4267-8456

\section{Baba Tshotsho \\ ORCID iD: https://orcid.org/0000-0002-4542-1752}

\section{Abstract}

The endeavour to impart sustainable knowledge in a postcolonial state is significantly hindered by legacies and cultures of subjectivity that are perpetuated long after declarations of independence. In the absence of the urban advantage, learners in educational institutions located in the margins tend to experience the heightened challenges of acquiring a sustainable education amid rurality. Learning English as a second language in former colonial spaces poses complex challenges for both the teacher and, especially, the learner due to the hegemony of English that thwarts epistemic access in various ways. This paper interrogates the possibilities of decolonizing the educational experience in the language classroom to maximize epistemic access through indigenizing English using translanguaging. The study engaged in a participatory observation of a purposively sampled first year class of university students doing an English for Specific Purposes course at the University of Fort Hare. While acknowledging the largely rural background of students in the sample, translanguaging was employed in the teaching of selected topics to measure content receptivity and student outcomes. The languages involved were English, isiXhosa and isiZulu. Through translanguaging, students participated with enthusiasm during discussions. In the 
absence of a negative affective filter and cognitive linguistic monitor that is characteristic of learning and speaking in English, students registered positive learning outcomes in both spoken and written assignments. During learning activities, facilitative crosslinguistic influence was acknowledged and explained. The findings established that students were conscious of the discriminatory and xenophobic nuances of scripted curricula as enacted by educators. Therefore, an attempt to redress this injustice through inclusion of, and appreciation for indigenous languages during learning through indigenizing English affirms students' identity, resulting in positive learning outcomes for marginalized and student populations in spaces of rurality.

Keywords; English, hegemony, indigenous languages, rurality, translanguaging; crosslinguistic influence; English classroom

\section{Introduction and Background}

Imparting sustainable knowledge in postcolonial settings is hindered by legacies and cultures of subjectivity that are perpetuated long after declarations of independence. Education systems in many African nation states are victim to these toxic legacies. Learners in the rural settings, who have suffered injustices since the colonial era, have remained in the margins and marginalised in terms of epistemic access. Rural schools have continued to be subject to inadequate resources and poorly trained teachers (Maforah \& Schulze 2012; Christie 2008). This presents a case of heightened challenges of acquiring a sustainable education, even when these learners present themselves for higher education in the universities. Research by Hurst (2017) and Zinn and Rodgers (2012) on colonial wounds and going beyond policy rhetoric, and The Soudien report (2008) on colonial practices embedded in learning and teaching illustrates these issues.

The curricula offered by higher educational institutions in South Africa do not adequately and practically address inequalities through pedagogic practices. Given the hegemony of English over indigenous languages, particularly in the rural classroom, there is an ever-urgent need to decolonize pedagogic practices; specifically, to align practice with the reality in the learning space. Central to that reality is the multilingual nature of the learning environment in South Africa (Prah 2007) and elsewhere (European Commission 2005; Cenoz and Gorter 2015; Portolés 2015). How do we 
decolonize the classroom, especially where measures like using indigenous languages for instruction are perceived with suspicion and fear, and where learners look down on their home language? One of the practical ways is embracing diversity: the language challenge. We attempt, in this paper, to synergise Euro-Western and African indigenous vehicles of epistemic access to reverse the disadvantages of rurality.

\section{The Problem of Epistemic Access}

Research indicates that approximately 10,000 hours are spent on the acquisition of the mother tongue up to the age of five years. In South Africa, the language of learning at university is largely English, yet only about $10 \%$ of the population cite English as their home language. Already, there is discord as learners' home language is not the language of learning. This can dehumanize the learning experience (Childs 2016), especially in cases where the home language of the learners is not tolerated or is forbidden (Mda 2004; Probyn 2001). This is despite research indicating that advantages abound where learners are free to use their home language in the learning space (Heugh 2008; Simkins \& Patterson 2005). How then can we facilitate access to knowledge in a case where the medium is not familiar? This is a huge question in Africa, which comprises multilingual, multicultural and multi-ethnic societies (Wolff 2017).

Colonial and apartheid history proved that language can be used to exclude, subjugate and oppress. These practices have continued in the postcolonial learning space (Prah 2007). Insisting on Standard English, and exclusive use of English in the classroom in spaces where the students' home language is, for example, isiXhosa or IsiZulu or SeSotho not only takes away the students' voice and power but also emasculates and silences a whole culture. It disempowers the learner (Alexander 2012). Singular elevation of English marginalises the indigenous knowledges that are embodied and embedded in languages sharing space with English. However, as Phaahla (2014) cautions, it is not a simple matter of eliminating English and replacing it with an indigenous language as this has the danger of replacing colonial monolingualism with African monolingualism; a practice that would obviously continue to subjugate other learners.

Since language equals identity, languaging is a process that both constructs and reflects the total person hence the need to acknowledge all the 
languages in the learning space through indigenizing English. In this paper, we sought innovative trajectories that go beyond theory in an attempt to influence classroom practice. The fundamental stakeholder in our quest for decolonizing the classroom is the student. The study disrupts hegemonic discourses of English as the superstrate and indigenous languages as substrates, thus the crosslinguistic influence (CLI) discourse that gives credence to other Englishes and other ways of interpretation. The objective is to terminate practices around language use that perpetuate the narrative of oppression and exclusion. Learning English as a second language in former colonial spaces poses complex challenges for both the teacher and, especially, the learner, due to the hegemony of English that thwarts epistemic access in various ways. This paper interrogates the possibilities of decolonizing the educational experience in the language classroom to maximize epistemic access through indigenizing English using translanguaging.

\section{Literature Review}

While education reforms have been central to the political agendas of the postcolonial states in Africa (Phaahla 2014) for several decades now, not much has been achieved. Among other spheres, this lack of meaningful reform has manifested in the language sector, especially in relation to the question of language of instruction. English has remained the major, and in other instances the only, medium of instruction for many post-colonial Southern African states. In Zimbabwe it has retained the prestigious position of language of wider communication (Nhongo et al. 2017). In South Africa, English remains the language of assessment even in those institutions of higher learning that claim to have adopted indigenous African languages for classroom instruction. With dwindling economies in most of Africa, the need to migrate for labour issues has also reinforced the position of English in the education systems of these nation states. Parents even prefer that their children learn English and in English (Peresuh \& Masuku 2002). This state of affairs mismatches the multilingual realities in Africa (Wolff 2017), especially in the postcolonial African learning spaces. Curriculum responsiveness (Slonimsky \& Shalem 2006; Moll 2004) remains elusive in the multilingual learning space that the South African university is.

The continued debate on the best medium of instruction for learners in post-colonial spaces in Africa has been due to findings of studies that indicate 
that learning in the mother tongue improves epistemic access (Web 2002; Prah 2002). The language question is not ' ...just about how we talk; it also impacts on what we talk about' (Wickham 2004:192). Thus, it impacts on knowledge systems and knowledge legitimation.

The persisting hegemony of English in former colonial spaces could easily be used to explain the undervaluing of knowledges from Africa and from Africans in South African Universities that Morreira (2015) points out. This is obviously the perpetuation of the injustices and inequalities of the preindependence apartness regime, where knowledge systems are hierarchicalised, and African knowledges and knowledge systems always occupy the foot of the ladder in that hierarchy. Morreira (2015:5) indicates that in African universities, knowledge production and knowledge legitimation in the humanities are still significantly linked to knowledge producer identity; 'While in the natural sciences the social position of the scientist is (supposedly) irrelevant to the possibility of scientific insight, in the humanities the ideal knower is always constructed socially'. This has resulted in the reproduction of Eurocentrism in the academy (Ndlovu-Gatsheni 2013/2016), and, at the same time, a perpetual disregard of knowledges from non-Eurocentric and nonAnglo-American sources.

Black learners often find themselves considered deficient in institutions where apartheid legacies still persist (Morreira 2015; Smit 2012). Learners in rural high schools who later attend universities in rural locations face compounded challenges. This translates to a much lower percentage of black South African students graduating than their white counterparts in South African Universities, and three times higher the percentage of black students dropping out than the white students (Council for Higher Education 2012). The challenge is that what Bourdieu (1986) points out that beyond socio-economic background of learners there are learners who fall victim to negative institutional cultures seems to still hold true in the post-colonial university; keeping the colonial wounds discussed by Hurst (2016) fresh.

As Morreira (2015:4) indicates, institutions of higher learning in South Africa have failed to adapt 'their teaching and learning to the cultural resources that (such) students bring' to the learning space. The whole system disregards the knowledges that permeate the learning environment as long as they are not the norm. Rural settings are equipped with rural epistemologies that would enrich the classroom if utilised. The first logical step to address these instances of 'hermeneutic injustice' (Fricker 2007) is dealing with the language question. 
Languaging plays a critical role in the legitimation of knowledges and knowledge systems, and, therefore, a central determinant of the success of epistemic access in the post-colonial education system.

This study explores the potential of translanguaging to change the state of affairs in the rural post-colonial classroom in South African universities. Translanguaging carries the promise of recognizing all the languages and linguistic resources presenting in the learning space; all the politically and historically situated sets of resources (Blommaert \& Rampton 2011; Heller 2007). It promises to bring to an end a 'hidden curriculum that favors some and excludes others' (Gamede 2005:58). Language can be perceived as part of a multi-modal repertoire for meaning construction (McKinney 2017). Therefore, if it is a resource, we can exploit it to our advantage to redress past injustices through translanguaging, a socially just pedagogy (Hurst \& Mona 2017) that questions the anglonormativity of higher education (Mckinney 2017) and humanizes the experiences of both the learners and teachers in the learning space (Childs 2016). Research (Heugh 2015; Garcia \& Wei 2015; Probyn 2015) indicates that translanguaging has strategies for improving epistemological access, and does so in a pedagogically sensitive manner (Lewis, Jones and Baker 2012). The study disrupts the norm of English as a superstrate and embraces the contribution of crosslinguistic influence in African Englishes (Zhou 2015).

This paper argues for indigenization of English using translanguaging in the English language classroom as a humanizing methodology in the $21^{\text {st }}$ century. It grapples with the question of how we can use crosslinguistic influence and translanguaging to humanize the learning experience for optimal epistemic access in spaces of rurality. We explore strategies that can be used in the classroom to nurture humanity while learning; to empower learners with a multiplicity of linguistic resources for epistemic access in the absence of the urban advantage.

\section{Theoretical Framework}

The study uses translanguaging as the theoretical lens to understand nuances of epistemic access. Translanguaging attempts to describe the ability of multilingual speakers to shuttle between languages, treating the diverse languages that form their repertoire as an integrated system (Canagarajah 2011). It involves planned use of the home languages of learners alongside the 
official language of learning (Childs 2016) to boost access to content (Heugh 2015; Garcia \& Wei 2015). The translanguaging pedagogic approach is in response to the language practices of the students, which include many dialects, accents, and high levels of multilingualism.

Translanguaging pedagogy goes beyond code switching to encourage students to cross between all known languages in multilingual classroom contexts (Makalela 2015); using code-meshing varieties and languages in essay writing (Canagarajah 2013); and developing 'concept glossaries' which stage the development of terms in African languages through translingual discussions (Madiba 2014). When students speak in their bilingual (even multilingual) homes, they use their full repertoire because no one is monitoring or hierarchizing their language practices. They simply use all of the features at their disposal. This is a common pattern of using language in all bilingual communities. Humanity can only be realised through repeated exposure to humanising practices that create an alternative narrative, construct a new identity and tell a new story. Translanguaging carries this potential to humanise the learning experience for both learners and instructors.

\section{Methodology}

The study used the qualitative approach. We engaged in a participatory observation of a purposively sampled first year class of university students doing an English for Specific Purposes course at the University of Fort Hare. The University of Fort Hare is located in Eastern Cape, South Africa. Eastern Cape is known as a rural province, and one of South Africa's poorest provinces (Matavire 2018). While acknowledging the largely rural background of students in the sample, translanguaging was employed in the teaching of selected topics to measure content receptivity and student outcomes. The languages involved were isiZulu, isiXhosa and English. The dominant language of learning at the University of Fort Hare is English while the dominant home language of the learners is isiXhosa. The other Southern African languages that were not part of the sampling but are significantly available in the learning environment are Afrikaans, SeSotho, Northern isiNdebele and Shona. The ESP class in the sample was a first year class of 150 students split into manageable groups of 50 for purposes of the study. Data was collected over a period of two months in the second semester of 2017. Six lectures were observed with two of the authors also participating in activities. 
The topics of focus were all centred on academic writing. The choice of academic writing as the overarching theme was prompted by the reality that university education is hinged on academic writing. However differently we may categorize and compartmentalize knowledges and the mode of their production, academia brings it all together through accountability and responsibility of the written report that presents, details and sums it all up for public consumption. It is, therefore, inevitably important that a student acquires the fundamentals of writing for them to survive and succeed in tertiary education. With that understanding in mind, academic writing was broken into the following; Writing an introduction, argumentation, your voice versus authorities and concluding an academic essay.

As put forward by Zhou (2015), English is indigenized by being allowed to express Zimbabwean and African identities and ideologies. According to Constant and Zimmerman (2007), ethnic identity is what makes a group of individuals different or the same in comparison to other groups. The expression of one's identity is key to self-worth that facilitates positive learning outcomes in the classroom. Two issues prompted our choice of sample for the exploration of the concept of indigenizing English through the teaching and learning of academic writing. First, the language classroom in the South African context is a melting pot of several languages owing to the multilingual nature of university campuses and classrooms by extension. Second, the English for Specific Purposes course is a special course that is underpinned by contextualization of all variables that congregate in the execution of learning and teaching. In that regard, a brief description of English for Specific Purposes as a course is useful in the justification of the methodology with particular reference to sample and data collection instruments used.

Given the currency of English as an international language, there is an ever-increasing demand for the English for Specific Purposes (ESP) course in universities. The objective is to equip students from different fields with requisite knowledge and skills for successful global interaction and participation. Early studies into ESP have defined it as a broad and flexible discipline with specific objectives and purposes that may vary from academic, professional to scientific (Robinson 1980). Further, since its foundation, ESP has been approached as the teaching of English for utilitarian purposes (Mackay \& Mountford 1978), an objective that directly echoes the global utility and functionality of English stated earlier.

The relevance of ESP to the foregoing inquiry into indigenizing Eng- 
lish in the classroom can be sufficiently highlighted and substantiated by reference to Hadley's (2006) argumentation that 'the key to teaching ESP is to focus on the ' $S$ ' for Specific'. While general English Language Teaching (ELT) focuses on universal and broad ranging aspects of English, ESP is concerned with specialized, contextualized language and practice. In conceptualizing how English can be indigenized in the classroom, we constructed what we named 'The $S$ Matrix' derived from the $S$ in ESP.

The S Matrix is a model illustration of the classroom environment in which six specific and specialized elements interact continuously with each other as a prelude and prerequisite for successful learning and teaching. All six elements are prefixed by the focus terms specific and specialized. In this case, the students are coming from a rural background in which rurality underpins their cognition. Their home language is an indigenous African language spoken with the pride that is characteristic of rural communities that have not been adulterated by urban individualism and pretence. Even the manner in which they speak or write English is not grounded in Anglonormative standards. There is significant crosslinguistic influence that points to rurality in the phonological, lexical and semantic structure and expression of their English, thus, making it a South African variety of English.

\section{The S Matrix}

Specific Students Specialised Instructional Material

Specific Context Specialised Language

Specific Content Specialised Contextualised Pedagogy

The S Matrix revolves around tailor making instruction according to the needs of the critical stakeholder in the learning process: the learner. As illustrated above, The S Matrix is underpinned by the specificity of student, context and content. The resulting expectation and experience is to customize instruction, language and methodology to suit the specific student in their particular 
context. The environment of the learner, therefore, including their language, is what prompted the choice of the ESP classroom as a possible and practical site for indigenizing English as it lends itself well to the concept of translanguaging and multilanguaging. To avoid teaching English, to use Long's (2005) words, for no purpose or for other people's purposes, it is practical to aim for indigenizing English to facilitate epistemic access. The danger with ignoring indigenous nuances and idiosyncrasies that consistently show up in English in multilingual contexts as crosslinguistic influence (Zhou 2015) is that you have to either dismiss them with contempt or explain their facilitative nature if any, and further state why you cannot use them. Both alternatives converge on contempt for indigenous languages, a situation that this paper is aimed at eradicating. Indigenizing English implies that all facilitative CLI is accepted and used to complete the speaker's repertoire for expression of thought.

\section{Discussion}

Given that ESP is a learner-centred approach (Dudley-Evans \& St. John 1998) our collection of data focused on the kind of data whose analysis shed light on individual learners, their differences as well as their specific linguistic and nonlinguistic needs vis-à-vis the language of instruction. Through translanguaging, students participated with enthusiasm during discussions. In the absence of a negative affective filter and cognitive linguistic monitor that is characteristic of learning and speaking exclusively in English, students achieved positive learning outcomes as evidenced by oral and written assignments following class discussions.

As indicated earlier in the literature, the problem of epistemic access stems from the pedagogic practices in multilingual settings. When we look at the classroom situation, we often encounter a disconnect between the learning context, the learners and the learning content. This difficult situation is further complicated by introducing the language question into the mix of complex variables that are already discordant. This is the reason we employed The $\mathrm{S}$ Matrix in preparation and execution of all tasks regarding the academic writing topics, namely writing an introduction, argumentation, your voice versus authorities and concluding an academic essay.

Following exposition and task guidelines, most of the work was done in groups to allow students to own the learning experience. Presentations of group tasks were alternated among the students in order to give voice to all 
within the group. Due to the rural background of the majority of the first years, codeswitching between isiXhosa and English was frequent in the discussions. Translation from isiXhosa to English was also engaged in; in some cases, the lecturer was asked to assist with vocabulary. Students presented freely with enthusiasm. The rigidity, hesitation and resentment that usually accompanies exclusive participation in English was absent. All responses were discussed exhaustively in all the languages of the group members prior to presentation. Turn-taking in presentations was a healthy option given that individuals coming from a history of subjugation are ever conscious of subtle innuendoes of dominance, whether personal, group, cultural or linguistic. Students are one group who are intricately linked to the continuous expression of dominance through scripted curricula that is packaged in colonial terms. While a shift from such curricula cannot be a guaranteed overnight job, pedagogic practices such as translanguaging have the capacity to disrupt the negative stream and continuity of hegemonic practices while paving way for more humane pedagogies.

\section{Indigenized Lexical Items}

To facilitate the participation of every member of the group, codeswitching and translation were used. The objective was to ensure that every member of the group had fully understood the task and, therefore, fully participated in finding the solution. During group tasks, it emerged that the choice and use of lexical items in multilingual contexts is governed by the African pragmatic context.

Students' use of lexical items in English as an additional language depends on their home language. Lexical choices are not dependent on Anglonormative paradigms though English has its foundations in England. Once English is spoken in an African linguistic situation surrounded by Bantu languages, it inevitably adopts the phonological, semantic and pragmatic features of its environment. For instance, as a result of semantic generalisation, the lexical item school is used to refer to all educational institutions including a technical college and a university. Mother is used to refer to any respected or elderly woman or even a female lecturer. Thing is used to refer to every conceivable object or concept whose explication is beyond immediate cognitive and linguistic grasp; it could be an issue/ problem/ concept. The lexical item child is used in place of learner or student. Kinship terms such as 
brother and sister can be integrated in an academic argument on where brother is any male and sister is any female. It is only when read in the context of South African communal life and Ubuntu ethos that one can understand such argumentation as not wrong but unique and rich as it reflects a particular worldview. This distinct choice and use of lexical items extends to use of conjunctions and discourse markers, as well as hedging and argumentation. Once guided on the correct use of these terms and their appropriate contexts, students feel confident to speak and write authentically. When they integrate aspects of their identity in speech and in writing, students feel that they are representing their authentic selves rather than acting up roles that they can hardly sustain in the brief lecture slot let alone for a lifetime career.

The various lexical, semantic, pragmatic examples that emerged during discussions and presentations confirmed that multilingual ESL students have an extensive lexicon acquired and learned during the SLA process. They compartmentalize vocabulary according to culture and context of socialization. Complex cognitive processes manifest as the selection and preference of certain lexical items in the learner's linguistic repertoire. Ignoring these realities thwarts epistemic access. Therefore, there is a need to appreciate English terms used in an indigenous sense, this one aspect in the development of South African English.

\section{Conclusion \& Recommendations}

It is axiomatic that students in rural settings find their academic courses significantly difficult even though they actually have the background and intellectual ability to handle these courses. The weakest link in this instance is language. While rurality is not a disadvantage, it presents a contemporary marginalisation akin to the social exclusion reminiscent of historical marginalisation under racial subjugation. Therefore, whether English is learnt for academic purposes in pre-occupational circumstances or it is learnt for occupational purposes in post-academic contexts, we posit that indigenization of English significantly facilitates epistemic access to counter rurality in two broad ways. First, allowing the English classroom to be a translanguagable site in itself frees students from the constraints of a strictly Anglo-normative approach to the teaching and learning of English language. The exclusive use of English in the learning of English itself or other courses is not only stifling, but has undercurrents of discrimination and covert oppression. These 
assumptions are of significance given that we cannot separate an individual from their culture and language. The three form an inseparable unit that defines one's identity. Therefore, to exclude one's language is to dismiss the speakers of that language and their culture by extension and implication.

Anglo-normative approaches dehumanize, alienate and further subjugate learners. Indigenizing English opens up a multiplicity of possibilities for decolonizing the classroom for positive learning outcomes. Students were conscious of the discriminatory and xenophobic nuances of scripted curricula as enacted by educators. Therefore, an attempt to redress this injustice through appreciation for indigenous languages during learning affirms students' identity resulting in positive learning outcomes for marginalized student populations. There is an urgent need for educators to create dialogic learning spaces in which all languages interface to facilitate epistemic access. There is further need to acknowledge crosslinguistic influence and the existence of local varieties of English through acknowledging crosslinguistic influence (CLI). Translanguaging can be embedded in the classroom without compromising the fundamental academic curriculum given that language is key to epistemic access. While our study confirmed that students participate actively in translanguaging classrooms where the use of English as a local variety is acceptable, there is need for further research into rural epistemologies with reference to language use. Further interrogation of performance in English medium courses and subjects is necessary since the objective is not to come top of the English class but rather to perform competently in subsequent courses taught in English regardless of geographical location. This would be the ultimate confirmation of epistemic access. Findings of this study should be interpreted as indicating a gap on innovation in the learning of English alongside indigenous languages. In summation, the global demand for highlevel proficiency in English in various fora is indicative of the significant role of English in the global economy hence the need for innovative contextualised pedagogies that address the challenges imposed by rurality on students.

\section{References}

Alexander N. 2012. The Centrality of the Language Question in the Social Sciences and Humanities in Post-apartheid South Africa: Revisiting a Perennial Issue. South African Journal of Science 108,9/10: Art. \#1443, 7 pages. https://doi.org/10.4102/sajs.v108i9/10.1443 
(Accessed on 29 October 2018.)

Bourdieu, P. 1986. The Forms of Capital. In Richardson, J. (ed.): Handbook of

Theory of Research for the Sociology of Education. New York:

Greenwood.

Canagarajah, S. 2011. Codemeshing in Academic Writing: Identifying Teachable Strategies of Translanguaging. Modern Language Journal 95: 401 - 417. https://doi.org/10.1111/j.1540-4781.2011.01207.x

Cenoz, J. \& D. Gorter 2015. Towards a Holistic Approach in the Study of

Multilingual Education. In Cenoz, J. \& D. Gorter (eds.): Multilingual

Education: Between Language Learning and Translanguaging.

Cambridge: Cambridge University Press.

Childs, M. 2016. Reflecting on Translanguaging in Multilingual Classrooms:

Harnessing the Power of Poetry and Photography. Educational Research for Social Change 5,1: 22 - 40.

http://dx.doi.org/10.17159/2221-4070/2016/v5i1a2

Christie, P. 2008. Opening the Doors of Learning: Changing Schools in South Africa. Johannesburg: Heinemann.

Council for Higher Education (CHE) 2012. 'Vital Statistics' Public Education. Pretoria: CHE.

Dudley-Evans \& A.J. St. John 1998. Developments in English for Specific Purposes: A Multi-disciplinary Approach. Cambridge University Press. Cambridge.

European Commission 2005. A New Framework Strategy for Multilingualism. Available at:

http://eur-lex.europa.eu/legalcontent/EN/TXT/?uri=uriserv:c11084

(Accessed on 13 December 2015.)

Fricker, M. 2007. Epistemic Injustice: Power and the Ethics of Knowing. Oxford: Oxford University Press.

https://doi.org/10.1093/acprof:oso/9780198237907.001.0001

Gamede, T. 2005. The Biography of 'Access' as an Expression of Human

Rights in South African Education Policies. PhD Thesis. Pretoria: University of Pretoria.

García, O. \& L. Wei 2015. Translanguaging, Bilingualism and Bilingual Education. In Wright, W., S. Boun \& O. García (eds.): Handbook of Bilingual Education. Malden, USA: John Wiley.

https://doi.org/10.1002/9781118533406.ch13 PMCid:PMC4400845

Heugh, K. 2008. Language Policy and Education in Southern Africa. In May, 
S. \& N.H. Hornberger (eds.): Encyclopedia of Language and Education. Volume 1. Dordrecht: Springer.

Heugh, K. 2015. Epistemologies in Multilingual Education: Translanguaging and Genre - Companions in Conversation with Policy and Practice. Language and Education 29,3: 280 - 285.

https://doi.org/10.1080/09500782.2014.994529

Lewis, G., B. Jones \& C. Baker 2012. Translanguaging: Origins and Development from School to Street and Beyond. Educational Research and Evaluation: An International Journal on Theory and Practice 18,7: 641 - 654. https://doi.org/10.1080/13803611.2012.718488

Long, M.H. (2005). Methodological Issues in Learner's Needs Analysis. In Long, M. (ed.): Second Language Needs Analysis. Cambridge: Cambridge

University Press. https://doi.org/10.1017/CBO9780511667299.002 Mackay, R. \& A.J. Mountford 1978. The Teaching of English for Specific Purposes: Theory and Practice. In Mackay, R. \& A.J. Mountford (eds.): English for Specific Purposes: A Case Study Approach. London: Longman.

Madiba, M. 2014. Promoting Concept Literacy through Multilingual Glossaries: A Translanguaging Approach. Bristol, UK: Multilingual Matters. https://doi.org/10.21832/9781783091669-007

Maforah, T.P. \& S. Schulze 2012. The Job Satisfaction of Principals of Previously Disadvantaged Schools: New Light on an Old Issue. South African Journal of Education 32,3: 227 - 239.

https://doi.org/10.15700/saje.v32n3a571

Makalela, L. 2015. Moving out of Linguistic Boxes: The Effects of Translanguaging Strategies for Multilingual Classrooms. Language and Education 29,3: 200 - 217.

https://doi.org/10.1080/09500782.2014.994524

Matavire, M. 2018. Eastern Cape Plans to Build Rural Economy. City Press. https://www.fin24.com/Economy/eastern-cape-plans-to-build-ruraleconomy-20180826-2

Mda, T. 2004. Multilingualism and Education. In Chisholm, L. (ed.): Changing Class: Education and Social Change in Post-apartheid South Africa. Cape Town: HSRC Press.

Moll, I. 2004. Curriculum Responsiveness: The Anatomy of a Concept. In Griesel, H. (ed.): Curriculum Responsiveness: Case Studies in Higher Education. Pretoria: SAUVCA. 
Morreira, S. 2015. Steps Towards Decolonial Higher Education in Southern Africa? Epistemic Disobedience in the Humanities. Journal of Asian and African Studies 1 - 15. https://doi.org/10.1177/0021909615577499

Ndlovu-Gatsheni, S. 2013. Empire, Global Coloniality and African Subjectivity. New York and Oxford: Berghahn Books.

Nhongo, R., C. Madoda, T. Baba \& S. Zhou 2017. Exploring the Second Language Teaching Strategies of Ndebele English Teachers in Selected Secondary Schools in Zimbabwe. Gender \& Behaviour 8626 - 8637.

Peresuh, M. \& J. Masuku 2002. The Role of the Primary Language in the Bilingual-Bicultural Education in Zimbabwe. Zambezia XXIX,1: 27 - 37. https://doi.org/10.4314/zjh.v29i1.6718

Phaahla, P. 2014. Indigenous African Languages as Agents of Change in the Transformation of Higher Education Institutions in South Africa: Unisa. Nordic Journal of African Studies 23,1: 31 - 56.

Portolés, L. 2015. Multilingualism and Very Young Learners: An Analysis of Pragmatic Awareness and Language Attitudes. Boston: De Gruyter.

Prah, K.K. 2002. The Rehabilitation of African Languages in Rehabilitating African Languages. Cape Town: The Centre for Advanced Studies of African Society.

Prah, K.K. 2007. Challenges to the Promotion of Indigenous Languages in South Africa. Cape Town: The Center for Advanced Studies of African Society.

Probyn, M. 2001. Teachers' Voices: Teachers' Reflections on Learning and Teaching through the Medium of English as an Additional Language in South Africa. International Journal of Bilingual Education and Bilingualism 4,4: 249 - 266. https://doi.org/10.1080/13670050108667731 (Accessed on 29 October 2018.)

Probyn, M.J. 2015. Pedagogical Translanguaging: Bridging Discourses in

South African Science Classrooms. Language and Education 29,3: 218 https://doi.org/10.1080/09500782.2014.994525

Robinson, P. 1980. ESP (English for Specific Purposes). New York: Pergamon.

Simkins, C. \& A. Patterson 2005. Learner Performance in South Africa: Social and Economic Determinants of Success in Language and Mathematics. Cape Town, South Africa: HSRC Press.

Slonimsky, L. \& Y. Shalem 2006. Pedagogic Responsiveness for Academic Septh. Journal of Education 40: 35 - 58. 
Smit, R. 2000. Toward a Clearer Understanding of Student Disadvantage in Higher Education: Problematising Deficit Thinking. Higher Education Research and Development 31,3: 369 - 380.

https://doi.org/10.1080/07294360.2011.634383

Web, V. 2002. English as a Second Language in South Africa's Tertiary Institutions: A Case Study at the University of Pretoria. World Englishes 21,1: 49 - 61. https://doi.org/10.1111/1467-971X.00231

Wickham, J. 2004. Something New in Old Europe? Innovations in EU-funded Social Research. Innovation 17,3: 187 - 204.

https://doi.org/10.1080/1351161042000241135

Wolff, H.E. 2017. Language Ideologies and the Politics of Language in Postcolonial Africa. Stellenbosch Papers in Linguistics Plus 52: 1 - 22. https://doi.org/10.5842/51-0-701

Zinn, D. \& C. Rodgers 2012. A Humanising Pedagogy: Getting Beneath the Rhetoric. Perspectives in Education 30,4: 76 - 87.

Zhou, S. 2015. Crosslinguistic Interface between English and Selected Zimbabwean Indigenous languages. PhD Thesis. University of Fort Hare, South Africa.

Sindiso Zhou Applied Linguistics Department of English \& Comparative Literature University of Fort Hare szhou@ufh.ac.za

Nhlanhla Landa Applied Linguistics Faculty of Social Sciences and Humanities. University of Fort Hare nlanda@ufh.ac.za

Baba Tshotsho Applied Linguistics Department of English \& Comparative Literature University of Fort Hare Btshotsho@ufh.ac.za 